УДК 338.1

\title{
И. И. Лямкин
}

Кемеровский институт (филиал) ФГБОУ ВО «РЭУ им. Г.В. Плеханова», Кемерово, e-mail: lii66@mail.ru

\section{О. И. Шершнева}

Кемеровский институт (филиал) ФГБОУ ВО «РЭУ им. Г.В. Плеханова», Кемерово, e-mail: daizy77@mail.ru

\section{СНИЖЕНИЕ РИСКА БАНКРОТСТВА НА ОСНОВЕ ИСПОЛЬЗОВАНИЯ МОДЕЛЕЙ ОЦЕНКИ ВЕРОЯТНОСТИ БАНКРОТСТВА ПРЕДПРИЯТИЙ В РОССИЙСКОЙ ЭКОНОМИКЕ}

Ключевые слова: банкротство, риски, управленческое решение, экономические модели.

В данной статье рассматриваются особенности оценки вероятности банкротства российских компаний с целью оптимизации их функционирования и снижения риска банкротства. Для этого используются модели, построенные на основе мультипликативного дискриминантного анализа и модели, базирующиеся на регрессионном логистическом анализе (logit-модели). Приведены альтернативные результаты расчетов вероятности банкротства с применением пятифакторной модели Э. Альтмана, моделей Р. Таффлера, Д. Фулмера, Зайцевой О.П., Савицкой Г.В., Дж. Ольсона, Хайдаршиной Г.А. Показано, что используемые модели дают неоднозначный результат. В связи с этим сделан вывод о необходимости осуществления мероприятий по повышению эффективности функционирования предприятия. Повторный расчет вероятности банкротства с учетом выполнения предлагаемых мероприятий показал положительный результат (низкую вероятность банкротства) для всех применяемых моделей. На основе проведенного исследования предложен алгоритм действий с целью недопущения банкротства компании, включающий мониторинг функционирования предприятия на предмет возможных рисков банкротства с использованием моделей оценки вероятности банкротства, построенных на основе как мультипликативного дискриминантного анализа, так и регрессионного логистического анализа, выявление проблемных зон, разработку и осуществление необходимых мероприятий.

\section{I. Lyamkin}

Kemerovo Institute (branch) Plekhanov Russian University of Economics, Kemerovo, e-mail: 1ii66@mail.ru

\section{O. I. Shershneva}

Kemerovo Institute (branch) Plekhanov Russian University of Economics, Kemerovo, e-mail: daizy77@mail.ru

\section{REDUCTION OF THE RISK OF BANKRUPTCY BASED ON THE USE OF MODELS OF EVALUATING THE PROBABILITY OF BANKRUPTCY OF ENTERPRISES IN THE RUSSIAN ECONOMY}

Keywords: bankruptcy, risks, management decision, economic models.

This article discusses the features of assessing the probability of bankruptcy of Russian companies in order to optimize their operation and reduce the risk of bankruptcy. For this purpose, models based on multiplicative discriminant analysis and models based on regression logistic analysis (logit models) are used. The alternative results of calculations of the bankruptcy probability using the five-factor model of $E$. Altman, the models of R. Taffler, D. Fulmer, Zaitseva O.P., Savitskaya G.V., J. Olson, Khaidarshina G.A. are given. It is shown that the models used give an ambiguous result. In this regard, it was concluded that it is necessary to take measures to improve the efficiency of the enterprise. Repeated calculation of the probability of bankruptcy in view of the implementation of the proposed measures showed a positive result (low probability of bankruptcy) for all the applied models. Based on the study, an algorithm of actions was proposed to prevent a company from bankruptcy, including monitoring the operation of an enterprise for possible bankruptcy risks using models for assessing the probability of bankruptcy based on both multiplicative discriminant analysis and regression logistic analysis, identifying problem areas, developing and the implementation of necessary activities. 


\section{Введение}

Согласно сведениям, представленным Федресурсом, начиная с 2014 г., примерно 13 тыс. российских компаний ежегодно признается банкротами [1, с. 5]. При этом по результатам проведения процедур банкротства удовлетворяются только 5-6\% требований кредиторов, включенных в реестр требований кредиторов [1, с. 14]. Поэтому представляется важной ранняя диагностика вероятности наступления банкротства, которая была бы доступна руководителям компаний и их контрагентам.

\section{Цель исследования}

Основная цель нашего исследования - провести оценку вероятности банкротства на примере конкретного предприятия, по результатам которой разработать алгоритм действий по снижению риска банкротства.

\section{Материал и методы исследования}

В настоящее время не только в России, но и в мире отсутствуют общепринятые методики оценки вероятности банкротств. Поэтому в целях получения более достоверных результатов мы использовали следующие наиболее известные российские и зарубежные модели:

1. Модели, построенные на основе мультипликативного дискриминантного анализа (Multiple-discriminant analysis - MDA).

1.1. Пятифакторная модель Альтмана [2] Алгоритм расчета:

$$
\begin{gathered}
Z=0,717 x_{1}+0,847 x_{2}+3,107 x_{3}+ \\
+0,42 x_{4}+0,995 x_{5},
\end{gathered}
$$

где $x_{1}$ - доля собственных оборотных средств в активах; $x_{2}$ - рентабельность активов; $x_{3}-$ рентабельность активов по прибыли до налогообложения; $x_{4}-$ коэффициент финансирования; $x_{5}-$ отношение выручки к активам.

Критерии оценки вероятности банкротства: $Z<1,23$ (высокая), $Z=1,23$ 2,89 (неопределенная), $Z>2,89$ (низкая).

1.2. Модель Р. Таффлера [3].

Алгоритм расчета:

$$
\mathrm{Z}=0,53 x_{1}+0,13 x_{2}+0,18 x_{3}+0,16 x_{4},
$$

где $x_{1}$ - соотношение прибыли от продажи и краткосрочных обязательств; $x_{2}$ - соотношение оборотных активов к заемному капиталу; $x_{3}$ - удельный вес краткосрочных обязательств в активах; $x_{4}$ - оборачиваемость активов.

Критерии оценки вероятности банкротства: $Z<0,2$ (высокая), $Z=0,2-0,3$ (неопределенная), $Z>0,3$ (низкая).

1.3. Модель Д. Фулмера [4].

Алгоритм расчета:

$$
\begin{gathered}
Z=5,528 x_{1}+0,212 x_{2}+0,073 x_{3}+1,27 x_{4}+ \\
+0,12 x_{5}+2,235 x_{6}+0,575 x_{7}+1,083 x_{8}+ \\
+0,984 x_{9}-3,075
\end{gathered}
$$

где $x_{1}$ - коэффициент соотношения нераспределенной прибыли прошлых лет к итогу баланса отчетного года; $x_{2}-$ оборачиваемость активов; $x_{3}$ - коэффициент соотношения прибыли до налогообложения и уплаты процентов к собственному капиталу; $x_{4}$ - коэффициент соотношения денежных средств к сумме краткосрочных и долгосрочных обязательств; $x_{5}$ - коэффициент соотношения долгосрочных обязательств к имуществу; $x_{6}-$ коэффициент соотношения краткосрочных обязательств к имуществу; $x_{7}$ - значение десятичного логарифма суммы материальных активов; $x_{8}-$ коэффициент соотношения оборотного капитала к обязательствам; $x_{0}$ - значение десятичного логарифма общей суммы прибыли до налогообложения и процентов к уплате к сумме процентов к уплате.

Критерии оценки вероятности банкротства: $Z<0$ (высокая), $Z>0$ (низкая).

1.4. Модель Зайцевой О.П. [5].

Алгоритм расчета:

$$
\begin{gathered}
K_{\text {факт }}=0,25 x_{1}+0,1 x_{2}+0,2 x_{3}+0,25 x_{4}+ \\
+0,1 x_{5}+0,1 x_{6} \\
K_{\text {норм }}=1,57+0,1 x_{6 \text { прошлого года }}
\end{gathered}
$$

где $x_{1}$ - коэффициент убыточности (отношение прибыли (убытка) до налогообложения к собственному капиталу); $x_{2}$ - соотношение кредиторской и дебиторской задолженностей; $x_{3}$ - соотношение краткосрочных обязательств с наиболее ликвидными активами; $x_{4}$ - доля прибыли до налогообложения в выручке; $x_{5}-$ коэффициент капитализации (финансовый леверидж); $x_{6}-$ соотношение активов и выручки. 
Критерии оценки вероятности банкротства:

$$
K_{\text {факт }}<K_{\text {норм (низкая) }}, K_{\text {факт }}>K_{\text {норм (высокая) }} \text {. }
$$

1.5. Модель Савицкой Г.В. [6]. Алгоритм расчета:

$$
\begin{gathered}
\mathrm{Z}=0,111 x_{1}+13,23 x_{2}+1,67 x_{3}+ \\
+0,515 x_{4}+3,8 x_{5}
\end{gathered}
$$

где $x_{1}$ - соотношение собственного капитала с оборотными активами; $x_{2}$ - доля оборотного капитала в общем капитале; $x_{3}$ - оборачиваемость совокупного капитала; $x_{4}$ - рентабельность активов; $x_{5}$ коэффициент автономии.

Критерии оценки вероятности банкротства:

$Z>8$ - риск банкротства отсутствует, $5<Z<8$-риск банкротства небольшой, $3<Z<5$ - риск банкротства средний, $1<Z<3$ - большой риск банкротства, $Z<1$ - максимальный риск банкротства.

2. Модели, построенные на основе регрессионного логистического анализа (logit-модели).

2.1. Модель Дж. Ольсона [7].

Алгоритм расчета:

$$
P=\frac{1}{1+e^{-Y}},
$$

где $P$ - вероятность банкротства (принимает значения от 0 до 1 );

$$
\begin{gathered}
Y=1,32+0,407 x_{1}+6,03 x_{2}+1,43 x_{3}- \\
-0,0757 x_{4}+2,37 x_{5}+1,83 x_{6}-0,258 x_{7}+ \\
+1,72 x_{8}+0,521 x_{9}
\end{gathered}
$$

где $x_{1}$ - натуральный логарифм отношения активов к индексу-дефлятору ВВП в стране; $x_{2}$ - доля заемного капитала в активах; $x_{3}$ - доля собственных оборотных средств в активах; $x_{4}-$ соотношение краткосрочных обязательств и оборотных активов; $x_{5}-$ рентабельность активов; $x_{6}-$ отношение чистой прибыли и амортизации к заемному капиталу; $x_{7}-$ фиктивная переменная (1, если чистый убыток; 0, если чистая прибыль); $x_{8}-$ фиктивная переменная -1 , если заемный капитал превышает активы; 0, если нет; $x_{9}$ - коэффициент роста чистой прибыли.
2.2. Модель Хайдаршиной (для промышленности) [8].

Алгоритм расчета:

$$
P=\frac{1}{1+e^{-Y}},
$$

где $P$ - вероятность банкротства (принимает значения от 0 до 1 );

$$
\begin{gathered}
Y=10,2137+0,0303 x_{1}+6,7543 x_{2}- \\
-3,7039 x_{3}-1,5985 x_{4}-0,564 x_{5}- \\
-0,1254 x_{6}-1,3698 x_{7}-6,3609 x_{8}- \\
-0,2833 x_{9}+2,5966 x_{10}-7,3087 x_{11}
\end{gathered}
$$

где $x_{1}$ - «возрастная характеристика» организации (0 - если предприятие создано более 10 лет назад, 1 - если менее 10 лет); $x_{2}$ - фактор «кредитной истории» организации (0 - если положительная «история», 1 - если отрицательная); $x_{3}$ - коэффициент текущей ликвидности; $x_{4}$ - соотношение прибыли до уплаты процентов и налогов с уплаченными процентами; $x_{5}$ - натуральный логарифм собственного капитала; $x_{6}$ - ставка рефинансирования ЦБ; $x_{7}$ - региональная принадлежность предприятия: 0 - Москва, Санкт-Петербург; 1 - другие регионы; $x_{8}$ - рентабельность активов; $x_{9}-$ рентабельность собственного капитала; $x_{10}$ - темп роста активов; $x_{11}$ - темп роста собственного капитала.

\section{Результаты исследования и их обсуждение}

Результаты применения вышеуказанных моделей за три года до банкротства предприятия представлены в табл. 1.

Как видно из таблицы, полученные результаты дают противоречивую оценку вероятности наступления банкротства. Большинство моделей (модель Р. Таффлера, модель Д. Фулмера, модель Савицкой Г.В., модель Дж. Ольсона, модель Хайдаршиной Г.А.) дает низкую оценку вероятности банкротства. Пятифакторная модель Э. Альтмана дает неопределенный результат, а модель Зайцевой О.П. свидетельствует о высоком риске банкротства.

Кроме абсолютных значений показателей риска важна, на наш взгляд, и их динамика. Полученные результаты показывают, что динамика показателей 
Таблица 1

Результаты оценки вероятности банкротства

\begin{tabular}{|c|c|c|c|}
\hline \multirow{2}{*}{$\begin{array}{c}\text { Модели оценки вероятности } \\
\text { банкротства }\end{array}$} & \multicolumn{3}{|c|}{ Вероятность банкротства } \\
\hline & 3 года назад & 2 года назад & 1 год назад \\
\hline \multirow[t]{2}{*}{ Пятифакторная модель Э. Альтмана } & $Z=1,824$ & $Z=2,107$ & $Z=1,648$ \\
\hline & \multicolumn{3}{|c|}{ Вероятность банкротства неопределенная } \\
\hline \multirow[t]{2}{*}{ Модель Р. Таффлера } & $Z=0,270$ & $Z=0,350$ & $Z=0,330$ \\
\hline & неопределенная & \multicolumn{2}{|c|}{ низкая } \\
\hline \multirow[t]{2}{*}{ Модель Д. Фулмера } & $Z=5,625$ & $Z=6,803$ & $Z=6,203$ \\
\hline & \multicolumn{3}{|c|}{ Вероятность банкротства низкая } \\
\hline \multirow[t]{2}{*}{ Модель Зайцевой О.П. } & $\begin{array}{l}K_{\text {факт }}=3,357 \\
K_{\text {норм }}=2,990\end{array}$ & $\begin{array}{l}K_{\text {факт }}=3,663 \\
K_{\text {норм }}=2,457\end{array}$ & $\begin{array}{l}K_{\text {факт }}=3,432 \\
K_{\text {норм }}=2,701\end{array}$ \\
\hline & \multicolumn{3}{|c|}{ Вероятность банкротства высокая } \\
\hline \multirow[t]{2}{*}{ Модель Савицкой Г.В. } & $Z=5,659$ & $\mathrm{Z}=8,453$ & $Z=9,454$ \\
\hline & Риск небольшой & \multicolumn{2}{|c|}{ Риск банкротства отсутствует } \\
\hline \multirow[t]{2}{*}{ Модель Дж. Ольсона } & $P=0,001$ & $P=0,001$ & $P=0,001$ \\
\hline & \multicolumn{3}{|c|}{ Вероятность банкротства низкая } \\
\hline \multirow[t]{2}{*}{ Модель Хайдаршиной Г.А. } & $P=0,001$ & $P=0,001$ & $P=0,001$ \\
\hline & \multicolumn{3}{|c|}{ Вероятность банкротства низкая } \\
\hline
\end{tabular}

у моделей, построенных на основе регрессионного логистического анализа, стабильна. Модели мультипликативного дискриминантного анализа, кроме модели Савицкой Г.В., за последний год демонстрируют отрицательную динамику, характеризующую повышение вероятности банкротства.

Учитывая вышеизложенное, полагаем, что нельзя сделать однозначный вывод о вероятности банкротства. Следуя принципу разумной осторожности следует осуществить мероприятия по повышению эффективности функционирования предприятия.

Наибольшее отрицательное влияние на результат в модели Зайцевой О.П. оказывает коэффициент соотношения краткосрочных обязательств с наиболее ликвидными активами. Поэтому с целью снижения риска банкротства необходимо улучшить работу с дебиторской задолженностью и изменить соотношение между дебиторской задолженностью и денежными средствами в пользу последних.

Взыскание дебиторской задолженности также позволит уменьшить неиспользуемые активы и снизить обязательства предприятия, что увеличит рентабельность активов и коэффициент финансирования. В результате улучшится результат по пятифакторной модели Э. Альтмана.

Результаты применения моделей оценки вероятности банкротства после осуществления вышеуказанных мероприятий представлены в табл. 2.

По данным табл. 2 видим, что предложенные мероприятия позволили обеспечить низкую вероятность банкротства в рамках всех реализованных моделей.

\section{Заключение}

Таким образом, в целях снижения вероятности банкротства руководству предприятия целесообразно постоянно проводить мониторинг функционирования предприятия на предмет возможных рисков банкротства, следуя следующему алгоритму:

1. Провести оценку вероятности банкротства предприятия с использованием моделей, построенных на основе как мультипликативного дискриминантного анализа, так и регрессионного логистического анализа.

2. Выявить модели оценки вероятности банкротства предприятия, результат которых свидетельствуют о риске банкротства. 


\section{Результаты оценки вероятности банкротства предприятия после оптимизационных мероприятий}

\begin{tabular}{|c|c|}
\hline Модели оценки вероятности банкротства & Вероятность банкротства \\
\hline \multirow[t]{2}{*}{ Пятифакторная модель Э. Альтмана } & $Z=2,987$ \\
\hline & Вероятность банкротства низкая \\
\hline \multirow[t]{2}{*}{ Модель Р. Таффлера } & $Z=0,552$ \\
\hline & Вероятность банкротства низкая \\
\hline \multirow[t]{2}{*}{ Модель Д. Фулмера } & $Z=7,287$ \\
\hline & Вероятность банкротства низкая \\
\hline \multirow[t]{2}{*}{ Модель Зайцевой О.П. } & $K_{\text {факт }}=1,496, K_{\text {норм }}=2,701$ \\
\hline & Вероятность банкротства низкая \\
\hline \multirow[t]{2}{*}{ Модель Савицкой Г.В. } & $Z=8,145$ \\
\hline & Вероятность банкротства низкая \\
\hline \multirow[t]{2}{*}{ Модель Дж. Ольсона } & $P=0,001$ \\
\hline & Вероятность банкротства низкая \\
\hline \multirow[t]{2}{*}{ Модель Хайдаршиной Г.А. } & $P=0,001$ \\
\hline & Вероятность банкротства низкая \\
\hline
\end{tabular}

3. Определить показатели этих моделей, которые оказывают наибольшее отрицательное влияние на результат оценки вероятности банкротства.

4. Рассчитать величины этих показателей, обеспечивающих получение результата с низкой вероятностью банкротства при реализации соответствующей модели.

5. Разработать и осуществить мероприятия по обеспечению соответствующей величины показателей.

\section{Библиографический список}

1. Статистический бюллетень ЕФРСБ. 31 декабря 2018 г. [Электронный ресурс]. Режим доступа: Ошибка! Недопустимый объект гиперссылки. (дата обращения: 24.05.2019).

2. Altman E. Financial ratios, discriminant analysis and the prediction of corporate bankruptcy // Journal of Finance. 1968. Vol. 23, №4, (September 1968). P. 589-609.

3. Taffler R..J Forecasting company failure in the UK using discriminant analysis and financial ratio data // Journal of the Royal Statistical Society: Series A (General). № 145 (3). 1982. P. 342-358.

4. Fulmer John G. et al.: A Bankruptcy Classification Model For Small Firms // Journal of Commercial Bank Lending, 1984. P. 25-37.

5. Зайцева О.П. Антикризисный менеджмент в российской фирме // Аваль. (Сибирская финансовая школа), 1998.

6. Савицкая Г.В. Экономический анализ: учебник. 14-е изд., испр. и доп. М.: ИНФРА-М, 2011.

7. Ohlson J.A. Financial Ratios and the Probabilistic Prediction of Bankruptcy // Journal of Accounting Research, 1980. № 18. P. 109--131.

8. Хайдаршина Г.А. Методы оценки риска банкротства предприятия: автореферат дис. ... канд. экон. наук. М., 2009. 